\title{
Chloroplast redox imbalance governs phenotypic plasticity: the "grand design of photosynthesis" revisited
}

\author{
Norman P. A. Hüner ${ }^{1,2}$, Rainer Bode ${ }^{1,2}$, Keshav Dahal ${ }^{1,2 t}$, Lauren Hollis ${ }^{1,2}$, Dominic Rosso ${ }^{1,2}$, \\ Marianna Krol ${ }^{1,2}$ and Alexander G. Ivanov ${ }^{1,2}$
}

${ }^{1}$ Department of Biology, Western University, London, ON, Canada

${ }^{2}$ The Biotron Centre for Experimental Climate Change Research, Western University, London, ON, Canada

\author{
Edited by: \\ Dario Leister, \\ Ludwig-Maximilians-University \\ Munich, Germany \\ Reviewed by: \\ Eva-Mari Aro, University of Turku, \\ Finland \\ Thomas Pfannschmidt, \\ Friedrich-Schiller-University Jena, \\ Germany \\ *Correspondence: \\ Norman P. A. Hüner, Department of \\ Biology, Western University, \\ London, Canada N6A 5B7. \\ e-mail: nhuner@uwo.ca \\ ${ }^{\dagger}$ Present address: \\ Keshav Dahal, Department of Cell and \\ Systems Biology, University of \\ Toronto at Scarborough, 1265 Military \\ Trail, Scarborough, Canada M1C 1A4.
}

\begin{abstract}
Sunlight, the ultimate energy source for life on our planet, enters the biosphere as a direct consequence of the evolution of photoautotrophy. Photoautotrophs must balance the light energy absorbed and trapped through extremely fast, temperature-insensitive photochemistry with energy consumed through much slower, temperature-dependent biochemistry and metabolism. The attainment of such a balance in cellular energy flow between chloroplasts, mitochondria and the cytosol is called photostasis. Photoautotrophs sense cellular energy imbalances through modulation of excitation pressure which is a measure of the relative redox state of $Q_{A}$, the first stable quinone electron acceptor of photosystem II reaction centers. High excitation pressure constitutes a potential stress condition that can be caused either by exposure to an irradiance that exceeds the capacity of $C, N$, and $S$ assimilation to utilize the electrons generated from the absorbed energy or by low temperature or any stress that decreases the capacity of the metabolic pathways downstream of photochemistry to utilize photosynthetically generated reductants. The similarities and differences in the phenotypic responses between cyanobacteria, green algae, crop plants, and variegation mutants of Arabidopsis thaliana as a function of cold acclimation and photoacclimation are reconciled in terms of differential responses to excitation pressure and the predisposition of photoautotrophs to maintain photostasis. The various acclimation strategies associated with green algae and cyanobacteria versus winter cereals and $A$. thaliana are discussed in terms of retrograde regulation and the "grand design of photosynthesis" originally proposed by Arnon (1982).
\end{abstract}

\section{Keywords: acclimation, excitation pressure, phenotype, photostasis, plasticity, redox sensing/signaling}

\section{INTRODUCTION}

Evolution has harnessed sunlight as the energy source for life because it is cheap, abundant, available in a very predictable manner and present in seemingly inexhaustible quantities when measured on a biological time scale. In photoautotrophic eukaryotes, the integral, thylakoid membrane, chlorophyll-pigment-protein complexes associated with photosystem II (PSII) and photosystem I (PSI) absorb, convert, and trap this energy as electrons (Figure 1). Intersystem photosynthetic electron transport (PET) connects the two photosystems through coupled oxidation-reduction of the plastoquinone (PQ) pool, the Cytochrome $\mathrm{b}_{6} / \mathrm{f}$ complex (Cyt $\mathrm{b}_{6} / \mathrm{f}$ ), and plastocyanin (PC). The net result of linear PET is the biosynthesis of reducing power in the form of NADPH and chemical energy in the form of ATP. Alternatively, electrons generated by PSI can be re-cycled through PSI cyclic PET which allows photosynthetic organisms to regulate ATP/NADPH ratios in the chloroplast (Shikanai, 2007; Johnson, 2011)

An astonishing characteristic of photosynthesis is that evolution has combined processes that exhibit extreme disparities in temperature sensitivities and rate constants that differ by at least 10 orders of magnitude (Hüner and Grodzinski, 2011). Consequently, photosynthetic organisms are predisposed to maintain a balance between the rates of light energy trapping through extremely fast (femtosecond to picosecond time scale) but temperatureinsensitive photophysical and photochemical processes of light absorption, energy transfer, and charge separation that generates electrons within the photosynthetic reaction centers versus the much slower but very temperature-sensitive processes of $\mathrm{C}$, $\mathrm{N}$, and S-metabolism (Figure 1), and ultimately growth and development that utilize the photosynthetic reductants. To overcome this disparity in reaction rates and temperature sensitivity, non-photochemical quenching mechanisms (NPQ) have evolved to dissipate any excess energy not used in photosynthesis as heat either through antenna quenching via the xanthophyll cycle (Demmig-Adams and Adams, 1992; Horton et al., 1996, 2008; Demmig-Adams et al., 1999) and/or reaction center quenching through PSII charge recombination (Krause and Weis, 1991; Walters and Horton, 1993; Hüner et al., 2006) to protect the PSII reaction center from over-excitation and ensure survival in a fluctuating light environment (Figure 1). The balance between energy trapping versus energy utilization and/or dissipation is called photostasis.

Photostasis can be represented by the equation, $\sigma_{\mathrm{PSII}} \cdot E_{\mathrm{k}}=\tau^{-1}$ (Falkowski and Chen, 2003; Hüner etal., 2003) where $\sigma_{\text {PSII }}$ is the effective absorption cross-section of PSII, $E_{\mathrm{k}}$ is the irradiance (I) at which the maximum photosynthetic quantum yield 

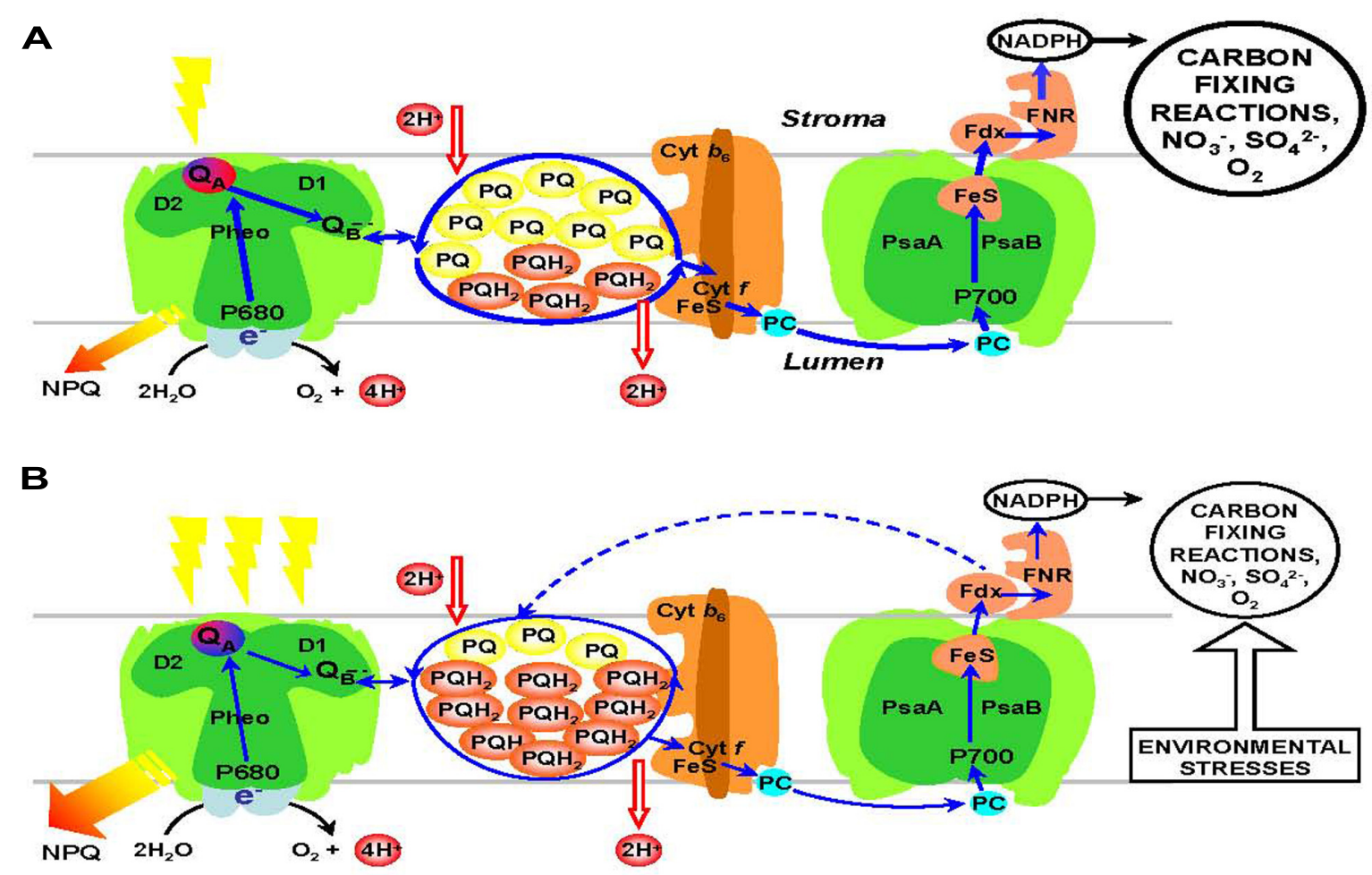

PSII-LHCII

Cyt b/f

PSI-LHCI

FIGURE 1 | General model of the photosynthetic electron transport chain. (A) Low excitation pressure conditions are indicated by a single yellow lighting bolt. Under these conditions, the PQ pool is largely in the oxidized state because the rate of photosynthetic electron transport plus NPQ match the rate of consumption of photosynthetic reductant, NADPH. Thick solid blue arrows indicate linear electron transport from photosystem II (PSII) to

photosystem I (PSI) to reduce $\mathrm{NADP}^{+}$to NADPH which is consumed by $\mathrm{C}, \mathrm{N}$, and $\mathrm{S}$ metabolism. Energy dissipated as heat through NPQ is minimal. PQ, plastoquinone (yellow); $\mathrm{PQH}_{2}$, plastoquinol (orange). (B) High excitation pressure conditions can be generated by either high light ( 3 lightning bolts) or by environmental stresses such as low temperature or nutrient stress which inhibit rates of metabolism. Under these conditions, the PQ pool is largely reduced to plastoquinol and energy dissipated through NPQ is increased. Consequently, rates of linear electron transport between PSII and PSI decrease (thin solid blue arrows) and enhance rates of PSI cyclic electron transport (broken blue arrow). balances photosynthetic capacity and $\tau^{-1}$ is the turnover rate of metabolic sinks, such as the assimilation of $\mathrm{C}, \mathrm{N}$, or $\mathrm{S}$ and ultimately by growth and development, that consume photosynthetic electrons. The product $\sigma_{\mathrm{PSII}} \cdot E_{\mathrm{k}}$ is, by and large, insensitive to temperature in the biologically significant range $\left(0-45^{\circ} \mathrm{C}\right)$ because it reflects the photophysical processes of light absorption and energy transfer within the light-harvesting antennae and core antennae pigment-protein complexes, which result in the induction of photochemistry and a charge separated state in the PSII reaction center. Although PSI absorbs light, its photochemical turnover rate is much higher than PSII and is normally not considered to be rate-limiting in PET (Ke, 2001) and therefore is not included in the equation for photostasis. In contrast, $\tau^{-1}$, which reflects biochemical reactions that consume photosynthetically generated electrons, is very temperature-sensitive (Melis, 1998; Hüner et al., 2003; Ensminger et al., 2006; Wilson et al., 2006; McDonald et al., 2011).

High excitation pressure (HEP) is a consequence of an imbalance between energy trapped through photochemistry versus energy either utilized through biochemistry or dissipated through NPQ and will occur whenever $\sigma_{\text {PSII }} \cdot E_{\mathrm{k}}>\tau^{-1}$ (Hüner et al., 2003;
Ensminger et al., 2006; Wilson et al., 2006). Since the oxidation of plastoquinol $\left(\mathrm{PQH}_{2}\right)$ by the Cyt $\mathrm{b}_{6} / \mathrm{f}$ complex is the ratelimiting step of intersystem PET (Haehnel, 1984), HEP results in an over-reduction of the PQ pool and the intersystem PET chain (Figure 1). This can be detected in vivo as an accumulation of closed PSII reaction centers and quantified by Chl a fluorescence as either 1-qP (Dietz etal., 1985; Hüner et al., 1998) or 1-qL (Hendrickson et al., 2004; Kramer et al., 2004; Baker, 2008) where $\mathrm{qP}$ and $\mathrm{qL}$ represent the photochemical quenching parameter (Schreiber et al., 1994; Baker, 2008). HEP occurs under any condition whereby $I>E_{\mathrm{k}}$, and can be generated by many environmental conditions including exposure to high light (HL) or any combination of HL or low temperature (LT), nutrient limitation or water status. Thus, theoretically, the effects of acclimation to any of these stresses on the structure and function of the photosynthetic apparatus should mimic acclimation to high irradiance (Hüner et al., 1998, 2003; Ensminger et al., 2006; Wilson et al., 2006).

Photoautotrophs respond to growth and development under HEP by remodeling the structure and function of the photosynthetic apparatus to balance cellular energy flow and establish a new photostatic state. According to the equation for photostasis, 
this can occur in the following ways: first, by enhancing sink capacity $\left(\tau^{-1}\right)$ through increased rates of energetically "useful" processes that consume photosynthetic reductants and fixed $\mathrm{C}$ such as respiration, $\mathrm{N}$-assimilation and ultimately growth which results in increased biomass production. Alternatively, photostasis can be achieved by decreasing the efficiency of light absorption and trapping ( $\sigma_{\text {PSII }}$ ) through energetically "wasteful" processes by either increasing rates of NPQ through stimulation of the xanthophyll cycle in the short-term (Demmig-Adams and Adams, 1992; Demmig-Adams et al., 1999) and/or reducing the physical size of the light-harvesting complex to decrease the probability of light absorption itself in the long-term (Hüner et al., 2003). However, the specific strategies employed to re-establish photostasis appear to be species-dependent and may result in alterations in the observable characteristics of an individual due to genotype versus environment interactions. Thus, a single genotype may exhibit variable phenotypes in response to changes in their environment. This is defined as phenotypic plasticity which reflects the integrated regulation of transcriptional, translational, and post-translational events with higher order processes associated with metabolism, growth, and photomorphogenesis. The latter is defined as the development of plant form and structure by light other than that utilized in photosynthesis. In contrast to photosynthesis, photomorphogenesis is regulated by specialized photoreceptors such as phytochrome and cryptochrome (Quail et al., 1995; Cashmore, 1997; Whitelam and Devlin, 1998). The focus of this review is on the role of light absorbed by the photosynthetic apparatus in governing phenotypic plasticity independent of photomorphogenesis. Fey et al. (2005) showed that redox signals from the photosynthetic apparatus can operate through retrograde signaling to affect nuclear gene expression independently of signaling through photoreceptors involved in photomorphogenesis. Furthermore, using various photomorphogenic mutants of Arabidopsis thaliana, Walters et al. (1999) showed that Arabidopsis mutants impaired in photomorphogenesis still retained the ability to adjust the structure and function of the photosynthetic apparatus in response to changes in growth irradiance. Thus, photoreceptors involved in photomorphogenesis are not required for the remodeling of the photosynthetic apparatus during the re-establishment of photostasis.

Energy sensing/signaling, retrograde regulation, and the molecular mechanisms that underlie phenotypic plasticity are complex, integrated cellular processes. Due to inherent restrictions with respect to length of this manuscript, we are not able to provide an exhaustive review of all pertinent published data in these areas of research. Rather, we focus on specific examples of acclimation to irradiance and temperature to illustrate how excitation pressure sensed within the chloroplast governs both local as well as distant molecular events to affect phenotypic plasticity.

\section{REGULATION OF PHENOTYPIC PLASTICITY IN GREEN ALGAE AND CYANOBACTERIA}

Growth and development of the green algae, Dunaliella tertiolecta, D. salina, and Chlorella vulgaris, under HL results in a typical yellow to yellow-green, HEP phenotype which is characterized by low Chl per cell and high ratios of $\mathrm{Chl} \mathrm{a/b}(\geq 10)$ compared to the typical green phenotype observed upon growth at low light (Sukenik et al., 1987; Escoubas et al., 1995; Maxwell et al., 1995a,b; Wilson and Hüner, 2000). Since the nuclear encoded LHCII polypeptides bind the bulk of the Chl in eukaryotic chloroplasts (Green et al., 2003), this HL phenotype reflects alterations in $\sigma$ PSII. Since the equivalent phenotype is generated by growth at LT and moderate irradiance which generates an excitation pressure comparable to the HL condition in D. salina and Chlorella vulgaris as well as the filamentous cyanobacterium, Plectonema boryanum, this phenotype is not a HL phenotype per se but rather should be considered a HEP phenotype (Maxwell et al., 1995a,b; Hüner et al., 1998, 2003; Miskiewicz et al., 2000, 2002; Wilson etal., 2003, 2006; Ensminger et al., 2006). The decrease in $\sigma_{\text {PSII }}$ in response to growth at HEP can be reconciled, in part, by the fact that Chlorella vulgaris exhibits a limited capacity to adjust photosynthetic carbon metabolism (Savitch et al., 1996) and growth rates (Wilson and Hüner, 2000) in response to HL. Similar results have been reported for P. boryanum (Miskiewicz et al., 2000, 2002). Thus, neither of these photosynthetic microbes is able to adjust their sink capacity $\left(\tau^{-1}\right)$ sufficiently to balance the increased energy input due to HL. Thus, to survive under HL conditions, these organisms decrease $\sigma_{\text {PSII }}$ by decreasing their efficiencies to harvest and trap light coupled with enhanced dissipation of absorbed excess light through NPQ. Similarly, LT inhibits growth due to thermodynamic constraints and to survive at LT, these organisms also decrease $\sigma_{\text {PSII }}$ to compensate for the lower growth rates thus lower sink capacity $\left(\tau^{-1}\right)$ for a given irradiance (Miskiewicz et al., 2000; Wilson and Hüner, 2000). Thus, the phenotypic congruence between acclimation to either LT or HL in these unicellular organisms appears to be a consequence of limitations in their capacity to adjust sink capacity in response to changes in temperature and light which generates a comparable HEP condition.

Complementary chromatic adaptation (CCA) is a phenotypic change exhibited by cyanobacteria in response to changes in ambient light quality (Kehoe and Gutu, 2006; Gutu and Kehoe, 2012). CCA is an historical misnomer and is actually an acclimation response to changes in light color (Kehoe and Gutu, 2006). When the filamentous cyanobacterium, Fremyella diplosiphon, is grown under green light, this cyanobacterium exhibits a red pigmented phenotype whereas it exhibits a blue-green phenotype when grown under red light. This acclimation response to light color is completely reversible and reflects alterations in the major light-harvesting pigments, phycoerythrin and phycocyanin, associated with phycobilisomes (Gantt, 1994). The regulation of CCA appears to involve the integration of a phytochrome-type photoreceptor pathway that is sensitive to green and red light in addition to a pathway that is redox-sensitive and involves PET (Kehoe and Gutu, 2006).

Coordinated regulation of Chl biosynthesis, Lhcb transcript abundance as well as Lhcb polypeptide accumulation is likely an important characteristic of acclimation to HEP in green algae. However, retrograde regulation examined in a gun4 mutant of Chlamydomonas reinhardtii indicates that down-regulation of LHC genes is governed post-transcriptionally with minimal transcriptional co-ordination (Formighieri etal., 2012). Chl b is required for the assembly and stabilization of LHCII (Thornber et al., 1994). Masuda et al. (2003) demonstrated that changes in 
the levels of $C A O$ transcripts, encoding the enzyme catalyzing the conversion of $\mathrm{Chl}$ a to $\mathrm{Chl} \mathrm{b}$, occur concomitantly with changes in $L h c b$ transcript abundance during acclimation to HL intensity in D. salina while the use of site specific inhibitors of the PET demonstrated that the redox state of the PQ pool regulates both $C A O$ and $L h c b$ transcript abundance. This is consistent with previous work demonstrating the regulation of $L h c b$ transcription by the redox state of the PQ pool in D. tertiolecta during photoacclimation (Escoubas et al., 1995). These studies are consistent with acclimation to HEP in green algae since HL has the potential to create imbalances in energy flow (Hüner et al., 1998; Ensminger et al., 2006). The pale yellow-green pigmentation of algal cultures acclimated to HEP may reflect limitations at the level of Chl biosynthesis. Studies in CAO over-expressors in higher plants have indicated that changes in $C A O$ transcription rates are sufficient to cause increases in the abundance of Lhcb polypeptides (Tanaka et al., 2001; Tanaka and Tanaka, 2007; Biswal et al., 2012) indicating that modulation of $\sigma_{\text {PSII }}$ may occur through transcriptional regulation of $\mathrm{Chl} b$ biosynthesis. Similarly, levels of CAO have been correlated to $\mathrm{Chl} b$ abundance and LHCII antenna size in D. salina (Masuda et al., 2002). It is currently unclear whether retrograde signals originating from the redox state of the PQ pool during acclimation to HEP directly coordinate Chl biosynthesis and LHCII abundance in green algae through transcriptional regulation of nuclear-encoded $L h c b$ and CAO genes in parallel or indirectly through a regulatory mechanism involving modulation of $\mathrm{Chl} b$ biosynthesis at the level of transcriptional control of CAO expression.

The mechanisms underlying the signal transduction pathways associated with retrograde regulation between the chloroplast and the nucleus in plants and green algae remain equivocal. However, recent evidence supports the role of heme, $\mathrm{Mg}$ protoporphyrin IX, HSP70, and HSP90 as important components in the retrograde signaling pathway (Strand et al., 2003a; von Gromoff et al., 2008; Kindgren et al., 2012). In addition, important biochemical evidence for the involvement of a protein phosphorylation cascade has been reported for D. salina (Escoubas et al., 1995; Masuda et al., 2003). Protein kinase inhibitors prevented the induction of $L h c b$ and $C A O$ expression during acclimation to low light intensity in $D$. salina (Masuda et al., 2003). Furthermore, cis-acting elements in the promoter region of algal Lhcb genes have been identified which are likely required for the plastidic redox regulation of nuclear gene expression (Escoubas et al., 1995; Chen et al., 2004). Furthermore, primary $\mathrm{C}$ and $\mathrm{N}$ metabolic pathways between chloroplasts and mitochondria and may also represent important communication pathways between these two organelles (Raghavendra et al., 1994; Gardestrom et al., 2002; Wilson et al., 2003). For example, inhibition of respiratory electron transport resulted in an increase in excitation pressure (Wilson et al., 2003) and decreased activation of Calvin cycle enzymes (Padmasree and Raghavendra, 2001). Furthermore, HEP stimulated the expression of the mitochondrial alternative oxidase (AOX; Rosso et al., 2009).

Does the generation of the yellow, HEP phenotype in Chlorella vulgaris represent a threshold response to varying excitation pressure? If so, one would expect a sigmoidal response for changes in $\mathrm{Chl}$ content, $\mathrm{Chl} \mathrm{a} / \mathrm{b}$ ratios and Lhcb content as a function of excitation pressure. This could be interpreted to indicate that the redox sensor(s) that respond to excitation pressure act as a "molecular on-off switch," that is, a minimum excitation pressure must be attained before nuclear encoded $L h c b$ genes are repressed by HEP through retrograde regulation. The proxies for phenotype included total $\mathrm{Chl} /$ cell and Lhcb content which exhibited a linear but negative relationship with increasing excitation pressure (Maxwell et al., 1995a,b; Wilson and Hüner, 2000). Concomitantly, $\mathrm{Chl} \mathrm{a} / \mathrm{b}$ ratios and xanthophyll cycle activity, and hence NPQ, also varied linearly but positively, as expected, as a function of increasing excitation pressure (Wilson and Hüner, 2000). Since all proxies for the phenotypic response of Chlorella vulgaris varied linearly as a function of excitation pressure, this indicates that the redox sensor(s) that govern the phenotypic response to excitation pressure in Chlorella vulgaris is not a "molecular on-off switch" but rather is analogous to a "molecular rheostat."

\section{ROLE OF CBF TRANSCRIPTION FACTORS IN THE REGULATION OF PHENOTYPIC PLASTICITY IN TERRESTRIAL PLANTS}

Brassica napus, winter cereals such wheat and rye grown at LTs exhibit a developmental shift from an elongated to a dwarf growth habit (Gray etal., 1997; Dahal etal., 2012a,b). However, the biomass of the dwarf plants are equal to or higher than the plants which exhibit the elongated phenotype due to a combination of increased leaf thickness, increased cytoplasmic volume coupled with decreased water content with no change in the total number of leaves (Hüner et al., 1984; Krol et al., 1984; Boese and Hüner, 1990; Strand et al., 1999; Gorsuch et al., 2010; Dahal et al., 2012a,b). Previously, it was presumed that this dwarf growth habit was strictly a response to growth at LT and this phenotype was used to select for freezing tolerance (Levitt, 1980). However, growth at HL but warm temperatures generates a comparable dwarf growth habit as observed at LT. Thus, it was shown that this dwarf phenotype is, in fact, governed by excitation pressure rather than by LT (Gray et al., 1997; Hüner et al., 1998). In contrast to green algae, Chlorella vulgaris and D. salina and the cyanobacterium, $P$. boryanum, these cold acclimated winter cultivars maintain photostasis by matching a high efficiency for light absorption ( $\sigma_{\text {PSII }}$ ) with an increased capacity for $\mathrm{CO}_{2}$ assimilation $\left(\tau^{-1}\right)$ through the up-regulation of transcription and translation of genes coding for Rubisco and the regulatory enzymes of cytosolic sucrose and fructan biosynthesis (Savitch et al., 2000a; Stitt and Hurry, 2002; Strand et al., 2003b; Ensminger et al., 2006; Dahal et al., 2012a,b) coupled with enhanced rates for leaf carbon export (Leonardos et al., 2003) and the suppression of photorespiration (Savitch et al., 2000b). These results are consistent with the global analyses of the cold acclimated $A$. thaliana metabolome which indicate a major reprogramming of carbon metabolism relative to non-acclimated plants (Gray and Heath, 2005). As a result, energy use efficiency is enhanced because the dissipation of absorbed light energy through NPQ is kept to a minimum while absorbed light energy used for C-assimilation is maximized resulting in increased biomass accumulation (Hüner et al., 1998; Stitt and Hurry, 2002; Strand et al., 2003b; Ensminger et al., 2006; Dahal et al., 2012a,b). This not only maximizes the chemical energy stored and carbon pool available for the renewed growth and reproduction in the spring but the accumulation of photosynthetic end-products such as sucrose also provides 
cryoprotectants to stabilize the cell membranes against freezing events during the winter (Stitt and Hurry, 2002).

What governs this complex, integrated phenomenon which appears to involve a system-wide change in morphology, physiology, and biochemistry of cold-tolerant crop plants? It has been suggested that cold- binding transcription factors/dehydration responsive element binding factors (CBFs/DREBs) control the phenotypic plasticity and freezing tolerance in cold-tolerant species (Jaglo-Ottosen et al., 1998; Liu et al., 1998; Kasuga et al., 1999; Gilmour et al., 2000, 2004; Savitch et al., 2005; Theocharis et al., 2012). Recently, we reported that the over-expression of a specific $C B F$ in Brassica napus, $B n C B F 17$, not only induces a dwarf phenotype but concomitantly enhances photosynthetic performance, the efficiency of energy conversion, water use efficiency, and biomass production comparable to that observed in cold acclimated B. napus (Savitch et al., 2005; Dahal et al., 2012a). We suggest that the transcription factor, $B n C B F 17$, may be either a master regulator or certainly a central component which governs the regulation of plant architecture, photosynthetic capacity, and energy conversion efficiency of crops. In Arabidopsis, the protein kinases, KIN10/KIN11, act as a central integrator of transcription networks associated with plant carbon metabolism and energy balance (Baena-Gonzalez et al., 2007). CBFs may interact with KIN10/KIN11 to affect photosynthetic performance in response to excitation pressure. However, the governance of phenotypic plasticity and photosynthetic performance by CBFs/DREBs in winter cultivars must also be integrated with the process of vernalization (Amasino, 2004; Sung and Amasino, 2005; Trevaskis et al., 2007; Trevaskis, 2010). Thus, gene regulation by CBFs extends well beyond its traditional role in cold acclimation and freezing tolerance. As discussed in detail by Murchie et al. (2009), elucidation of the mechanisms which govern the dynamic nature of energy partitioning between energetically "useful processes" involved in C and $\mathrm{N}$-assimilation for biomass and seed production versus apparently energetically "wasteful processes" such as the dissipation of absorbed light energy as heat through NPQ to optimize plant survival remains a major challenge in maximizing crop productivity. Modulation of $C B F$ expression levels may provide important new insights into potential molecular and genetic approaches focused on the maintenance or even the enhancement of plant productivity under suboptimal growth conditions associated with climate change (Dahal et al., 2012a).

\section{EXCITATION PRESSURE GOVERNS CHAOTIC LEAF VARIEGATION PATTERNS}

The A. thaliana chaotic variegated mutant, immutans (im), displays unpredictable white and green sectoring patterns due to differential stability of thylakoid membranes during chloroplast biogenesis and are considered plastid autonomous (Rodermel, 2002; Yu et al., 2007). IMMUTANS (IM) is encoded by a single nuclear gene which is translated into a $35 \mathrm{kD}$ thylakoid polypeptide where it functions as a plastid terminal oxidase (PTOX). Cloning and characterization of IM revealed that it is related to the mitochondrial inner membrane AOX (Carol et al., 1999; Wu et al., 1999; McDonald et al., 2011) which oxidizes ubiquinol and reduces molecular oxygen (Vanlerberghe and McIntosh, 1997). By analogy, it has been suggested that IM is induced under stress conditions and oxidizes $\mathrm{PQH}_{2}$ and reduces $\mathrm{O}_{2}$ to water (Carol et al., 1999; Wu et al., 1999; Carol and Kuntz, 2001; Rodermel, 2001; McDonald et al., 2011). Consequently, PTOX is considered to be the essential oxidase which participates in the chlororespiratory pathway (Cournac et al., 2000a,b). Recently, Fu et al. (2012) reported that AOX1a and AOX2 can functionally substitute for PTOX in the immutans mutant of $A$. thaliana and rescue the variegated phenotype. It is proposed that IM is not only essential for carotenoid biosynthesis and chlororespiration but it is also acts as a "safety valve" in the photoprotection of PSII (Niyogi, 1999; Cournac et al., 2000a,b; Rodermel, 2001; Joet et al., 2002; Peltier and Cournac, 2002).

Recently, we reported specific growth conditions that completely suppressed the variegated phenotype of $i m$ such that it exhibited an "all green" phenotype indistinguishable from the wild type (WT) even though neither IM expression nor IM accumulation was detected (Rosso et al., 2006). By exploiting this phenomenon and comparing im knockout plants with WT, as well as a $6 \times$ and $16 \times$ over-expressor of $I M$, we reported that in mature, fully expanded leaves of $A$. thaliana, IM (PTOX) cannot compete with $\mathrm{P} 700^{+}$for PSII-generated electrons under optimal growth conditions. We concluded that under optimal growth conditions, PTOX cannot act as a simple "safety valve" in A. thaliana leaves exhibiting full photosynthetic competence (Rosso etal., 2006). Our conclusion is consistent with that of Heyno et al. (2009) who reported that over-expression of PTOX in tobacco induced rather than ameliorated oxidative stress. In contrast to these reports, there are numerous reports of specific abiotic stress conditions which induce the expression and accumulation of PTOX in alpine plant species (Streb et al., 2005), the halophile, Thellungiella halophila (Stepien and Johnson, 2009) as well as the marine cyanobacterium, Synechococcus WH8102 and marine green alga, Ostreococcus (Bailey et al., 2008; Cardol et al., 2008; Grossman et al., 2010). Furthermore, Baena-Gonzalez et al. (2003) reported that deletion of tobacco plastid $p s b A$ triggers an upregulation of the thylakoid-associated $\mathrm{NAD}(\mathrm{P}) \mathrm{H}$ dehydrogenase complex as well as PTOX.

All oxygenic photoautotrophs exhibit the presence of IM (PTOX) in their genomes (McDonald et al., 2011). How can the apparent conflicting reports regarding the function of IM (PTOX) be reconciled? Meta-transcriptome analyses of PTOX indicated that PTOX expression is primarily developmentally regulated in Arabidopsis rather than by stress (Rosso et al., 2006). To address the role of IM (PTOX) in leaf development, we developed a sensitive, high resolution, non-destructive imaging technique by which we could quantify the extent of variegation as a function of time. This allowed us to quantify the effects of growth irradiance and temperature on the extent of variegation as a function of developmental time. Using this technique, we were able to show that the absence of IM is necessary but not sufficient to explain variegation in $A$. thaliana. In fact, the extent of variegation is governed by excitation pressure not only in im but also in the other Arabidopsis variegated mutants such as spotty, var1, and var2 (Rosso et al., 2009). The biogenesis and assembly of thylakoid membranes requires tight co-ordination between the de novo synthesis of $\mathrm{Chl}$ and other pigments, lipids as well as chloroplast and nuclear encoded proteins (Eberhard et al., 2008; Sakamoto et al., 2008). This raises an 
important developmental question as to how a photoautotroph mitigates the potential damaging effects of photo-oxidative stress during the biogenesis and assembly of its photosystems prior to the establishment of a fully functional photosynthetic apparatus. In WT plants, protection from photo-oxidative stress is provided through transient stimulation of non-photochemical dissipation of excess energy through the xanthophyll cycle (Demmig-Adams and Adams, 1992; Murchie et al., 2009) as shown during early greening in barley (Krol et al., 1999) as well as the induction of myriad plant oxidative stress genes including AOX (Aluru et al., 2009). However, im seedlings are unable to biosynthesize photoprotective carotenoids involved in the xanthophyll cycle (Wetzel et al., 1994). Although IM cannot compete with $\mathrm{P} 700^{+}$for PSIIgenerated electrons in mature leaves that are photosynthetically competent (Rosso et al., 2006), its presence is essential to minimize excitation pressure and the potential for photo-oxidative damage during the very early stages in the assembly and biogenesis of the photosynthetic apparatus prior to the attainment of full photosynthetic competence (Rosso et al., 2006, 2009).

To account for the variable and unpredictable patterns of leaf variegation in immutans, we suggest the presence of a gradient of excitation pressure within the developing leaf primordia during light-dependent chloroplast biogenesis: the data indicate that if excitation pressure in a particular developing sector is lower than 0.2 , chloroplast biogenesis proceeds normally and an "all green" sector(s) with a LEP phenotype will develop; however, if excitation pressure in a particular developing sector exceeds 0.2 , thylakoid assembly and chloroplast biogenesis is inhibited and white sectors with a HEP phenotype will develop (Rosso et al., 2009). This implies a threshold-dependence for the sensor(s) that govern the HEP versus the LEP phenotype in im in response to changes in excitation pressure, and therefore, appear to act as "molecular onoff switches" in contrast to that observed for the regulation of the HEP phenotype in the green alga, Chlorella vulgaris.

There appears to be a consensus that PTOX not only acts as the terminal oxidase in the chlororespiratory pathway (Cournac et al., 2000a,b) but also acts an important alternative photosynthetic electron sink under any condition where PSI is acceptor-limited. Under these conditions, the induction of PTOX as an alternative, $\mathrm{O}_{2}$-dependent pathway for photosynthetic electron flow would mitigate any PSI limitation and protect PSII from overexcitation by oxidizing $\mathrm{PQH}_{2}$ and reducing $\mathrm{O}_{2}$ to water (Grossman et al., 2010; McDonald et al., 2011). This is consistent with the recent results of Formighieri etal. (2012) who reported that a gun4 mutant of Chlamydomonas reinhardtii exhibits a significant decrease in PSI/PSII ratios coupled with an increase in PTOX activity which may protect the gun 4 mutant from HEP under conditions where PSI levels may be limiting. In addition, the biogenesis and assembly of the photosynthetic apparatus appears to be coordinated with mitochondrial redox balance as indicated by the fact AOX expression is modulated by excitation pressure originating within the chloroplast (Rosso et al., 2009) indicating redox communication between chloroplasts and mitochondria.

Unlike photoacclimation or LT acclimation discussed above, chaotic leaf variegation in A. thaliana is a consequence of destabilization of the developing photosynthetic apparatus by excitation pressure during thylakoid membrane assembly and chloroplast biogenesis rather than an example of remodeling of the photosynthetic apparatus by adjusting either $\sigma_{\text {PSII }}$ or $\tau^{-1}$. The control of variegation in various Arabidopsis mutants represents an excellent example of how chloroplast redox sensing/signaling, through excitation pressure, mediates the interaction of the nuclear encoded IMMUTANS gene with its environment to affect chloroplast biogenesis, leaf development, and subsequent phenotype.

\section{WHAT IS THE PRIMARY SITE(S) FOR SENSING CHLOROPLAST ENERGY IMBALANCE?}

Research with cyanobacteria (Fujita, 1997), green algae (Escoubas et al., 1995; Maxwell et al., 1995a,b; Hüner et al., 1998; Wilson et al., 2003), and plants (Anderson et al., 1995; Pfannschmidt, 2003; Fey etal., 2005; Woodson and Chory, 2008; Brautigam et al., 2009; Pesaresi etal., 2009; Rochaix, 2011) indicates that a key component of redox sensing/signaling associated with the photosynthetic apparatus is the PQ pool, a mobile electron carrier that shuttles electrons from PSII to the Cyt $b_{6} / f$. This is based, in part, on experiments where the characteristic, yellow-green, HL phenotype of green algae brought about by photoacclimation, that is, acclimation to high irradiance, could be mimicked by chemically modulating the redox status of the intersystem PQ pool. This is traditionally accomplished by using minimal concentrations of the PET inhibitors, either 2,5-dibromo-3-methyl-6-isopropylbenzoquinone (DBMIB) or 3( $3^{\prime}, 4^{\prime}$-dichlorophenyl)-1,1-dimethylurea (DCMU; Escoubas et al., 1995; Pfannschmidt et al., 1999; Pfannschmidt, 2003; Wilson et al., 2003; Piippo et al., 2006). Since DBMIB inhibits the oxidation of $\mathrm{PQH}_{2}$ by the Cyt $b_{6} / f$ complex, PSII keeps the PQ pool reduced in the light. This induces the HL phenotype which is characterized by low Chl content per cell, high $\mathrm{Chl}$ a/b ratio ( $>10)$, accumulation of the carotenoid-binding protein (Cbr; Krol et al., 1997) but suppression of both Lhcb2 expression and Lhcb2 accumulation through retrograde regulation of nuclear encoded genes by the chloroplast in Chlorella vulgaris and D. salina. Since this HL phenotype is also mimicked by growth of Chlorella vulgaris and D. salina at LT (Maxwell et al., 1995a,b; Wilson et al., 2006), we designate this as a HEP phenotype. In contrast, since DCMU prevents the exit of electrons from PSII reaction centers into the PQ pool, PSI is able to keep the PQ pool oxidized in the light. Under these conditions, cells exhibit a LEP phenotype characterized by a high $\mathrm{Chl}$ content per cell, low Chl a/b ratio (3.0-3.5), and high levels of Lhcb2 expression and Lhcb2 accumulation (Escoubas et al., 1995; Maxwell et al., 1995a,b; Wilson et al., 2003). This LEP phenotype can also be generated by growth at either low irradiance or high temperature but moderate irradiance in Chlorella vulgaris (Maxwell et al., 1995a,b; Hüner et al., 1998; Wilson et al., 2003). Since $\mathrm{Q}_{\mathrm{A}}$, the first stable quinone electron acceptor within the PSII reaction center is considered to be in rapid equilibrium with the PQ pool of intersystem electron transport (Dietz et al., 1985; Schreiber et al., 1994; Maxwell et al., 1995a,b; Baker, 2008), we have assumed that the PQ pool is the primary redox sensor that governs changes in excitation pressure (Hüner et al., 1998, 2003, 2006; Oquist and Huner, 2003; Ensminger et al., 2006; Morgan-Kiss et al., 2006; Wilson et al., 2006; McDonald et al., 2011). However, our earlier report for the regulation of 
HEP and LEP phenotypes in the filamentous cyanobacterium, $P$. boryanum, indicated that the PQ pool is probably not the major site from which redox signals emanate to control pigmented phenotype through modulation of the composition and structure of phycobilisomes in this cyanobacterium (Miskiewicz et al., 2000, 2002). This is consistent with the recent report by Piippo et al. (2006) who reported that the PQ pool is not the major redox sensor regulating photoacclimation in A. thaliana and that the primary redox signals probably emanate from the acceptor-side of PSI.

The assumption that the combination of DCMU and DBMIB identifies the redox state of the PQ pool as the primary site of chloroplast redox sensing/signaling ignores the potential contributions of other PET components to redox sensing/signaling. Indeed, recent research in Arabidopsis suggests that the redox state of ferredoxin ( $\mathrm{Fd}$ ), thioredoxins ( $\mathrm{Trx}$ ), and peroxiredoxins on the acceptor-side of PSI (Dietz, 2003, 2008; Dietz and Scheibe, 2004) as well as the generation of reactive oxygen species (ROS; Apel and Hirt, 2004; Wagner et al., 2004) may constitute a complex network of redox senors/signals involved in the retrograde pathway of communication from the chloroplast to the nucleus (Koussevitzky etal., 2007; Fernandez and Strand, 2008; Jung and Chory, 2010). In fact, Piippo et al. (2006) suggest that the reducing side of PSI may represent the major source of chloroplast redox signaling involved in retrograde regulation. Furthermore, PSII itself may also contribute to retrograde regulation of nuclear genes through the generation of singlet oxygen (Apel and Hirt, 2004; Wagner et al., 2004; Nott et al., 2006; Lee et al., 2007; Fernandez and Strand, 2008) and thus, may contribute to redox regulation by excitation pressure. Using a combination of inhibitors, uncouplers, and antimycin A, Chen et al. (2004) identified two different sensors involved in the retrograde signal transduction pathway in D. salina. The transthylakoid membrane potential (pmf) appeared to govern gene expression in response to changes in irradiance on a short time scale $(<4 \mathrm{~h})$, whereas on time scales of $8 \mathrm{~h}$ or longer, the redox state of the PQ pool appeared to become the more prominent sensor. Thus, the regulation of gene expression and phenotypic plasticity through excitation pressure in green algae must represent a complex interacting intracellular network of sensors and signal transduction pathways.

However, in terrestrial crop plants and A. thaliana, a similar complex, intracellular network must be integrated with an equally complex sensor/signal transduction pathway that extends over long distances from leaf chloroplasts to meristematic tissue such as the crown in cereals. This long distance sensor/signaling pathway must convey information regarding the redox status of the leaf chloroplasts to regulate meristematic cell division and differentiation and affect plant growth, development, and morphology (Gray et al., 1997). There is a growing body of evidence that the environment has a significant impact on cell development not only in leaves (Rosso et al., 2009) but also in roots (Tsukagoshi et al., 2010) as well as anthers (Kelliher and Walbot, 2012; Whipple, 2012) through modulation of cellular redox state. Furthermore, there is growing support in the literature that although hydrogen peroxide is a toxic molecule generated by various stress conditions in plants (Mittler et al., 2004), it is also an important molecule involved in systemic signaling and acclimation to excitation pressure in plants (Karpinski et al., 1999; Mullineaux et al., 2000; Fryer et al., 2003; Mullineaux et al., 2006; Geisler et al., 2006).

\section{THE "GRAND DESIGN OF PHOTOSYNTHESIS"}

Figure 2 represents a simplified model that attempts to summarize the central role of the photosynthetic apparatus as a major sensor of excitation pressure that is modulated by irradiance (sunlight) and LT (snowflake) in photoautotrophs. It is clearly established that the PET chain is an important source of redox signals involved in intracellular redox signaling. There appears to be a consensus that, within the PET chain, several potential redox sensors appear to exist including PSII, the PQ pool, the thylakoid proton motive force (pmf) as well as the acceptor-side of PSI. The latter would include the redox status of Fd, Trx, peroxiredoxins, $\mathrm{H}_{2} \mathrm{O}_{2}$, as well as metabolic intermediates of carbon metabolism. The acceptor-side of PSI appears to be a major site of redox sensing/signaling in the chloroplast. These sensors may contribute to varying extents and may act independently or in concert to initiate retrograde signaling to the nucleus to affect transcriptional regulation of nuclear photosynthetic genes. The end result of such retrograde redox sensing/signaling in response to changes in excitation pressure is the remodeling of the structure and function of the photosynthetic apparatus to re-establish photostasis.

In addition to intracellular retrograde redox sensing/signaling, redox signals from the chloroplast must be transmitted to various meristematic regions such as the crown tissue within winter cereals to affect plant morphology (e.g., dwarf phenotype). Consequently, this redox signaling pathway probably involves long distance transport via the plant vascular system. Possible components of this long distance signaling pathway may include but are not restricted to hormones, $\mathrm{H}_{2} \mathrm{O}_{2}$, and photosynthetic end-products such as sucrose. The rate of long distance transport from source to sink as well as sink activity reflected in rates of growth and development can, in turn, feedback regulate the extent of chloroplastic excitation pressure. Thus, we suggest that phenotypic plasticity governed by excitation pressure initially sensed in leaf chloroplasts is the result not only of local remodeling of the photosynthetic apparatus, but also the regulation of remote meristematic regions to affect plant morphology.

Thirty years ago, Arnon (1982) proposed the concept of a "grand design of photosynthesis" which was re-introduced by Anderson et al. (1995). Anderson et al. (1995) conclude that the "grand design of photosynthesis with exquisite regulation ensures that the responses of both photoreceptors and photosystems II and I, acting as their own light sensors, are inextricably linked with feedback metabolic responses from photosynthesis itself, which allow plants to respond to both sudden and sustained fluctuations in environmental cues." This notion has been supported either directly (Anderson et al., 1995; Hüner et al., 1998; Ensminger et al., 2006; Wilson et al., 2006; Pfannschmidt and Yang, 2012) or indirectly (Pfannschmidt, 2003; Fey et al., 2005; Murchie et al., 2009; Lepisto and Rintamaki, 2012). Although the precise nature of the redox sensors and signal transduction pathways associated with excitation pressure remain to be elucidated, we maintain that the data summarized in this review are consistent with the notion of a "grand design of photosynthesis." Consequently, we suggest that, 


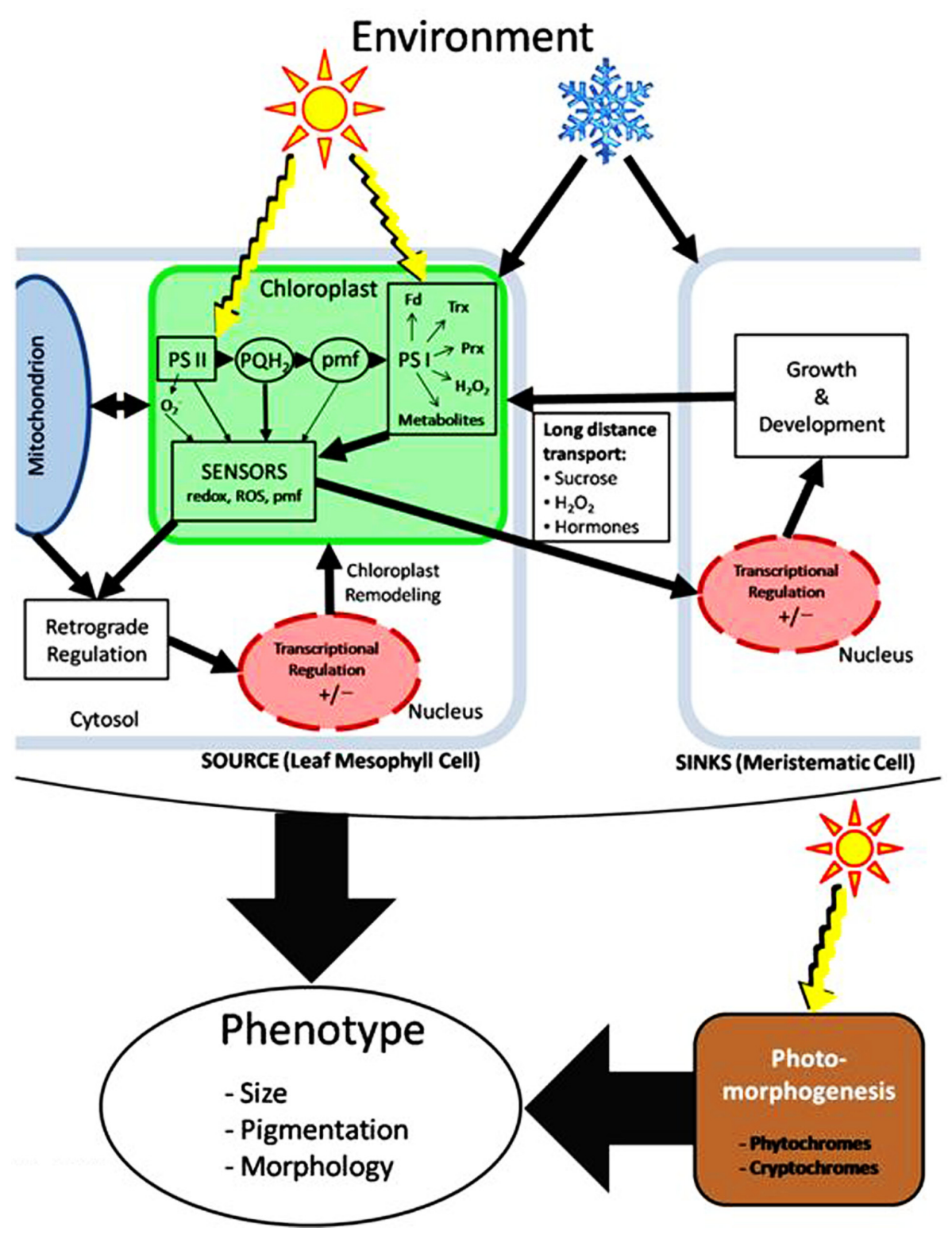

FIGURE 2 | A model illustrating the environmental regulation of phenotypic plasticity via chloroplast redox sensing coupled to both intracellular and long distance signal transduction. Light is the ultimate source of energy for photoautotrophs. Energy imbalances generated either by changes in high light (sun) or low temperature (snowflake) are sensed in the chloroplast by modulation of the redox state of the photosynthetic apparatus. Such redox information is exchanged between chloroplasts and mitochondria through carbon metabolism. Intracellular redox imbalances in chloroplasts and mitochondria are conveyed to the nucleus through retrograde regulation to affect remodeling of the photosynthetic apparatus to re-establish photostasis and energy balance. The remodeling of the photosynthetic apparatus may be reflected in changes phenotype exhibited as alterations in pigmentation in certain algae and cyanobacteria. In vascular plants, information regarding chloroplast redox imbalance is also conveyed to distant sinks such as meristematic regions of a plant to affect growth and development. This occurs through long distance signaling via the vascular system. Such information also contributes to the regulation of phenotypic plasticity reflected in changes in vascular plant morphology. In plants, distant sink limitations induced by low temperature can also be important in feedback regulation of energy balance in chloroplasts in source leaves. Thus, phenotypic plasticity is the result of the integration of both photosynthetic as well as photomorphogenic events. PSII, photosystem II; PSI, photosystem I; $\mathrm{POH}_{2}$, reduced plastoquinone; pmf, proton motive force; Fd, ferredoxin; Trx, thioredoxins; Prx, peroxiredoxins. in addition to its traditional role as the energy transformer for the biosphere, the photosynthetic apparatus should also be considered a major energy sensor which is modulated by environmental cues and plays a major role in the regulation of phenotypic plasticity (Figure 2).
Although all photoautotrophs can sense changes in their environment through the modulation of excitation pressure, we suggest that it is source-sink relationships that ultimately modulate the extent of excitation pressure which then governs the observed phenotype of photoautotrophs during growth at 
either HL or LT. Thus, photoautotrophs must integrate information regarding changes in light quality through photoreceptors with changes in light as an energy source through the redox state of the photosynthetic apparatus to affect plant growth and morphology (Anderson et al., 1995; Fryer et al., 2003; Lepisto and Rintamaki, 2012; Figure 2). Since sunlight represents the ultimate energy source for our biosphere, greater understanding of the role of the chloroplast as an energy sensor which governs energy partitioning and energy utilization efficiency as well as phenotypic plasticity will be essential for the maintenance

\section{REFERENCES}

Aluru, M. R., Zola, J., Foudree, A., and Rodermel, S. R. (2009). Chloroplast photooxidation-induced transcriptome reprogramming in Arabidopsis immutans white leaf sectors. Plant Physiol. 150, 904-923.

Amasino, R. (2004). Vernalization, competence, and the epigenetic memory of winter. Plant Cell 16, 2553-2559.

Anderson, J. M., Chow, W. S., and Park, Y.-I. (1995). The grand design of photosynthesis: acclimation of the photosynthetic apparatus to environmental cues. Photosyn. Res. 46, 129-139.

Apel, K., and Hirt, H. (2004). Reactive oxygen species: metabolism, oxidative stress, and signal transduction. Ann. Rev. Plant Biol. 55, 373-399.

Arnon, D. I. (1982). Sunlight, earth life: the grand design of photosynthesis. Sciences 22, 22-27.

Baena-Gonzalez, E., Allahverdiyeva, Y., Svab, Z., Maliga, P., Josse, E.-M., Kuntz, M., et al. (2003). Deletion of the tobacco plastid psbA gene triggers an upregulation of the thylakoidassociated $\mathrm{NAD}(\mathrm{P}) \mathrm{H}$ dehydrogenase complex and the plastid terminal oxidase (PTOX). Plant J. 35, 704-716.

Baena-Gonzalez, E., Rolland, F., Thevelein, J. M., and Sheen, J. (2007). A central integrator of transcription networks in plant stress and energy signalling. Nature 448, 938-942.

Bailey, S., Melis, A., Mackey, K. R. M., Cardol, P., Finazzi, G., van Dijken, G., etal. (2008). Alternative photosynthetic electron flow to oxygen in marine Synechococcus. Biochim. Biophys. Acta 1777, 269-276.

Baker, N. R. (2008). Chlorophyll fluorescence: a probe of photosynthesis in vivo. Ann. Rev. Plant Biol. 59, 89-113.

Biswal, A. K., Pattanayak, G. K., Pandey, S. S., Leelavathi, S., Reddy, V. S., Govindjee, X., et al. (2012). Light intensity-dependent modulation of chlorophyll b biosynthesis and photosynthesis by overexpression of chlorophyllide a oxygenase in tobacco. Plant Physiol. 159, 433-449.

Boese, S. R., and Hüner, N. P. A. (1990). Effect of growth temperature and temperature shifts on spinach leaf morphology and photosynthesis. Plant Physiol. 94, 18301836.

Brautigam, K., Dietzel, L., Kleine, T., Stroher, E., Wormuth. D., Dietz, K.-J., et al. (2009). Dynamic plastid redox signals integrate gene expression and metabolism to induce distinct metabolic states in photosynthetic acclimation in Arabidopsis. Plant Cell 21, 2715-2732.

Cardol, P., Bailleul, B., Rappaport, F. Derelle, E., Bacal, D., Breyton, C. et al. (2008). An original adaptation of photosynthesis in the marine green alga Ostreococcus. Proc. Natl. Acad. Sci. U.S.A. 105, 7881-7886.

Carol, P., and Kuntz, M. (2001). A plastid terminal oxidase comes to light: implications for carotenoid biosynthesis and chlororespiration. Trends Plant Sci. 6, 31-36.

Carol, P., Stevenson, D., Bisanz, C., Breitenbach, J., Sandmann, G., Mache, R., et al. (1999). Mutations in the Arabidopsis gene IMMUTANS cause a variegated phenotype by inactivating a chloroplast terminal oxidase associated with phytoene desaturation. Plant Cell 11, 57-68.

Cashmore, A. R. (1997). The cryptochrome family of photoreceptors.

Chen, Y.-B., Durnford, D. G., Koblizek, M., and Falkowski, P. G. (2004). Plastid regulation of Lhcbl transcription in the chlorophyte alga Dunaliella tertiolecta. Plant Physiol. 136, 3737 3750.

Cournac, L., Josse, E. M., Joet, T., Rumeau, D, Redding, K., Kuntz, M., et al. (2000a). Flexibility in photosynthetic electron transport: a newly identified chloroplast oxidase involved in chlororespiration. Philos. Trans. R. Soc. Lond. B Biol. Sci. 355, 1447-1454.

Cournac, L., Redding, K., Ravanel, J., Rumeau, D., Josse, E. M., Kuntz, M., etal. (2000b). Electron flow Plant Cell Environ. 20, 764-767.

or possibly even the enhancement of plant biomass for energy and crop productivity for food under suboptimal growth conditions associated with climate change (Murchie et al., 2009; Dahal et al., 2012a).

\section{ACKNOWLEDGMENTS}

NPAH acknowledges the financial support of the Natural Sciences and Engineering Research Council of Canada, the Canada Research Chairs Programme and the Canada Foundation for Innovation.

between photosystem II and oxygen in chloroplasts of photosystem I-deficient algae is mediated by a quinol oxidase involved in chlororespiration. J. Biol. Chem. 275, 17256 17262.

Dahal, K., Gadapati W., Savitch, L. V., Singh, J., and Hüner, N. P. A. (2012a). Cold acclimation and BnCBF17over-expression enhance photosynthetic performance and energy conversion efficiency during long-term growth of Brassica napus under elevated $\mathrm{CO} 2$ conditions. Planta 236, 1639-1652.

Dahal, K., Kane, K., Gadapati, W., Webb, E., Savitch, L. V., Singh, J., et al. (2012b). The effects of phenotypic plasticity on photosynthetic performance in winter rye, winter wheat and Brassica napus. Physiol. Plant. 144, 169-188.

Demmig-Adams, B., and Adams, W. W. III (1992). Photoprotection and other responses of plants to high light stress. Ann. Rev. Plant Physiol. Plant Mol. Biol. 43, 599-626.

Demmig-Adams, B., Adams W. W. III, Ebbert, V., and Logan, B. A. (1999). "Ecophysiology of the xanthophyll cycle", in Advances in Photosynthesis. The Photochemistry of Carotenoids, Vol. 8, eds H. A. Frank, A. J. Young, G. Britton, and R. J. Cogdell (Dordrecht: Kluwer Academic Publishers), 245-269.

Dietz, K.-J. (2003). Plant peroxiredoxins. Ann. Rev. Plant Biol. 54, 93-107.

Dietz, K.-J. (2008). Redox signal integration: from stimulus to networks and genes. Physiol. Plant. 133, 459-468.

Dietz, K.-J., and Scheibe, R. (2004). Redox regulation: an introduction. Physiol. Plant. 120, 1-3.

Dietz, K.-J., Schreiber, U., and Heber, U. (1985). The relationship between the redox state of QA and photosynthesis in leaves at various carbon-dioxide, oxygen and light regimes. Planta 166 219-226.

Eberhard, S., Finazzi, G., and Wollman, F.-A. (2008). The dynamics of photosynthesis. Ann. Rev. Genetics 42, 463-515.
Ensminger, I., Busch, F., and Hüner, N. P. A. (2006). Photostasis and cold acclimation: sensing low temperature through photosynthesis. Physiol. Plant. 126, 28-44.

Escoubas, J.-M., Lomas, M., LaRoche, J., and Falkowski, P. G. (1995). Light intensity regulates cab gene transcription via the redox state of the plastoquinone pool in the green alga, Dunaliella tertiolecta. Proc. Natl. Acad. Sci. U.S.A. 92, 1023710241.

Falkowski, P. G. and Chen, Y. -B. (2003). "Photoacclimation of light harvesting systems in eukaryotic algae", in Advances in Photosynthesis and Respiration, Vol. 13, Light Harvesting Antennas in Photosynthesis, eds. B. R. Green and W. W. Parson (Dordrecht: Kluwer Academic Publishers), 423-447.

Fernandez, A. P., and Strand, A. (2008). Retrograde signaling and plant stress: plastid signals initiate cellular stress responses. Curr. Opin. Plant Biol. 11, 509-513.

Fey, V., Wagner, R., Brautigam, K., and Pfannschmidt, T. (2005). Photosynthetic redox control of nuclear gene expression. J. Exp. Bot. 56, 1491-1498.

Formighieri, C., Ceol, M., Bonente, G., Rochaix, J.-D., and Bassi, R. (2012). Retrograde signaling and photoprotection in a gun 4 mutant of Chlamydomonas reinhardtii. Mol. Plant doi: 10.1093/mp/sss051 [Epub ahead of print].

Fryer, M. J., Ball, L., Oxborough, K., Karpinski, S., Mullineaux, P. M., and Baker, N. R. (2003). Control of ascorbate peroxidase 2 expression by hydrogen peroxide and leaf water status during excess light stress reveals a functional organisation of Arabidopsis leaves. Plant J. 33, 691-705.

Fu, A., Liu, H., Yu, F., Kambakam, S., Luan, S., and Rodermel, S. (2012). Alternative oxidases (AOX1a and AOX2) can functionally substitute for plastid terminal oxidase in Arabidopsis chloroplasts. Plant Cell 24, 1579-1595. 
Fujita, Y. (1997). A study on the dynamic features of photosystem stoichiometry-accomplishments and problems for future studies. Photosyn. Res. 53, 83-93.

Gantt, E. (1994) "Supramolecular membrane organization", in Advances in Photosynthesis. Molecular Biology of Cyanobacteria, Vol. 1, ed. D. A. Bryant (Dordrecht: Kluwer Academic Publishers), 119-138.

Gardestrom, P., Igamberdiev, A. U., and Raghavendra, A. S. (2002). "Mitochondrial functions in the light and significance to carbon-nitrogen interactions", in Advances in Photosynthesis and Respiration. Photosynthetic Nitrogen Assimilation and Associated Carbon Respiratory Metabolism, Vol. 12, eds. C. H. Foyer and G. Noctor (Dordrecht: Kluwer Academic Publishers), 151-172.

Geisler, M., Kleczkowski, L. A., and Karpinski, S. (2006). A universal algorithm for genome-wide in silicio identification of biologically significant gene promoter putative cis-regulatory-elements; identification of new elements for reactive oxygen species and sucrose signaling in Arabidopsis. Plant J. 45, 384-398.

Gilmour, S. J., Fowler, S. G., and Thomashow, M. F. (2004). Arabidopsis transcriptional activators $\mathrm{CBF} 1$, $\mathrm{CBF}$, and $\mathrm{CBF} 3$ have matching functional activities. Plant Mol. Biol. 54, 767-781.

Gilmour, S. J., Sebolt, A. M., Salazar, M. P., Everard, J. D., and Thomashow, M. F. (2000). Overexpression of the Arabidopsis CBF3 transcriptional activator mimics multiple biochemical changes associated with cold acclimation. Plant Physiol. 124, 1854-1865.

Gorsuch, P. A., Pandey, S., and Atkin, O. K. (2010). Temporal heterogeneity of cold acclimation phenotypes in Arabidopsis leaves. Plant Cell Environ. 33, 244-258.

Gray, G. R., Chauvin, L.-P., Sarhan, F., and Hüner, N. P. A. (1997). Cold acclimation and freezing tolerance (A complex interaction of light and temperature). Plant Physiol. 114, 467-474.

Gray, G. R., and Heath, D. (2005). A global reorganization of the metabolome in Arabidopsis during cold acclimation is revealed by metabolic fingerprinting. Physiol. Plant. 124, 236-248.

Green, B. R., Anderson, J. M., and Parson, W. W. (2003). "Photosynthetic membranes and their light harvesting antennas", in Advances in Photosynthesis and Respiration, Vol. 13, Light Harvesting Antennas in Photosynthesis, eds. B. R. Green and W. W.
Parson (Dordrecht: Kluwer Academic Publishers), 1-28.

Grossman, A. R., Mackey, K. R. M. and Bailey, S. (2010). A perspective on photosynthesis in the oligotrophic oceans: hypothesis concerning alternative routes of electron flow. $J$. Phycol. 46, 629-634.

Gutu, A., and Kehoe, D. M. (2012) Emerging perspectives on the mechanisms, regulation, and distribution of light color acclimation in cyanobacteria. Mol. Plant 5, 1-13.

Haehnel, W. (1984). Photosynthetic electron transport in higher plants. Ann. Rev. Plant Physiol. 35, 659-693.

Hendrickson, L., Furbank, R. T., and Chow, W. S. (2004). A simple alternative approach to assessing the fate of absorbed light energy using chlorophyll fluorescence. Photosyn. Res. 82 , 73-81.

Heyno, E., Gross, C.M., Laureau, C. Culcasi, M., Petrie, S. and KreigerLiszkay, A. (2009) Plastid alternative oxidase (PTOX) promotes oxidative stress when overexpressed in tobacco. J. Biol. Chem. 284, 31174-31180.

Horton, P., Johnson, M. P., Perez-Bueno, M. L., Kiss, A. Z., and Ruban, A. V. (2008). Photosynthetic acclimation: does the dynamic structure and macro-organisation of photosystem II in higher plant grana membranes regulate light harvesting states? FEBS J. 275, 1069-1079.

Horton, P., Ruban, A. V., and Walters, R. G. (1996). Regulation of light harvesting in green plants. Ann. Rev Plant Physiol. Plant Mol. Biol. 47, 655-684.

Hüner, N. P. A., Elfman, B., Krol, M., and MacIntosh, A. (1984). Growth and development at cold hardening temperatures. Chloroplast ultrastructure, pigment content and composition. Can. J. Bot. 62, 53-60.

Hüner, N. P. A. and Grodzinski, B. (2011). "Photosynthesis and photoautotrophy" in Comprehensive Biotechnology, Vol. 1, ed. M. MooYoung (Elsevier), 315-322.

Hüner, N. P. A., Ivanov, A. G., Sane, P. V., Pocock, T., Krol, M., Balseris, A., et al. (2006). "Photoprotection of Photosystem II: reaction centre quenching versus antenna quenching", in Advances in Photosynthesis and Respiration, Vol. 21, Photoprotection, Gene Regulation and Environment, eds. B. Demmig-Adams, W. W. Adams III, and A. K. Mattoo (Dordrecht: Springer), 155-173.

Hüner, N. P. A., Öquist, G., and Melis, A. (2003). "Photostasis in plants, green algae and cyanobacteria: the role of light harvesting antenna complexes", in Advances in Photosynthesis and Respiration, Vol. 13, Light Harvesting Antennas in Photosynthesis, eds. B. R. Green and W. W. (Dordrecht: Kluwer Academic Publishers), 401-421.

Hüner, N. P. A., Öquist, G., and Sarhan, F. (1998). Energy balance and acclimation to light and cold. Trends Plant Sci. 3, 224-230.

Jaglo-Ottosen, K. R., Gilmour, S. J., Zarka, D. G., Schabenberger, O., and Thomashow, M. F. (1998). Arabidopsis $\mathrm{CBF} 1$ overexpression induces COR genes and enhances freezing tolerance. Science 280, 104-106.

Joet, T., Cournac, L., Peltier, G., and Havaux, M. (2002). Cyclic electron flow around photosystem I in C3 plants. In vivo control by the redox state of chloroplasts and involvement of the NADH-dehydrogenase complex. Plant Physiol. 128, 760-769.

Johnson, G. N. (2011). PSI cyclic electron transport in higher plants. Biochim. Biophys. Acta. 1807, 906-911.

Jung, H.-S., and Chory, J. (2010). Signaling between chloroplasts and the nucleus: can a systems biology approach bring clarity to a complex and highly regulated pathway? Plant Physiol. 152, 453-459.

Karpinski, S., Reynolds, H., Karpinska, B., Wingsle, G., Creissen, G., and Mullineaux, P. (1999). Systemic signaling and acclimation in response to excess excitation energy in Arabidopsis. Science 284, 654-657.

Kasuga, M., Liu, Q., Miura, S., Yamaguchi-Shinozaki, K., and Shinozaki, K. (1999). Improving plant drought, salt, and freezing tolerance by gene transfer of a single stressinducible transcription factor. Nat. Biotechnol. 17, 287-291.

Ke, B. (2001). "Photosystem I introduction", in Advances in Photosynthesis. Photobiochemistry and Photobiophysics, Vol. 10, ed. Govindjee (Dordrecht: Kluwer Academic Publishers), 419-430.

Kehoe, D. M., and Gutu, A. (2006). Responding to color: the regulation of complementary chromatic adaptation. Ann. Rev. Plant Biol. 57, 127-150.

Kelliher, T., and Walbot, V. (2012). Hypoxia triggers meiotic fate acquisition in maize. Science 337, 345-348. Kindgren, P., Noren, L., Barajas Lopez, J. dD., Shaikhali, J., and Strand, A. (2012). Interplay between HEAT SHOCK PROTEIN 90 and HY5 controls PhANG expression in response to the GUN5 plastid signal. Mol. Plant 5, 901-913.

Koussevitzky, S., Nott, A., Mockler, T. C., Hong, F., Sachetto-Martins, G.,
Surpin, M., et al. (2007). Signals from chloroplasts converge to regulate nuclear gene expression. Science 316, 715-719.

Kramer, D. M., Johnson, G., Kiirats, O., and Edwards, G. E. (2004). New fluorescence parameters for the determination of QA redox state and excitation energy fluxes. Photosyn. Res. 79, 209-218.

Krause, G. H., and Weis, E. (1991). Chlorophyll fluorescence and photosynthesis: the basics. Ann. Rev. Plant Physiol. Plant Mol. Biol. 42, 313-349.

Krol, M., Griffith, M., and Hüner, N. P. A. (1984). An appropriate physiological control for environmental temperature studies: comparative growth kinetics for winter rye. Can. J. Bot. 62, 1062-1068.

Krol, M., Ivanov, A. G., Jansson, S., Kloppstech, K., and Hüner, N. P. A. (1999). Greening under high light or cold temperature affects the level of xanthophyll-cycle pigments, early light-inducible proteins, and light-harvesting polypeptides in wild-type barley and the chlorina f2 mutant. Plant Physiol. 120, 193-203.

Krol, M., Maxwell, D. P., and Hüner, N. P. A. (1997). Exposure of Dunaliella salina to low temperature mimics the high light-induced accumulation of carotenoids and the carotenoid binding protein (Cbr). Plant Cell Physiol. 38, 213-216.

Lee, K. P., Kim, C., Landgraf, F., and Apel, K. (2007). EXECUTER1- and EXECUTER2-dependent transfer of stress-related signals from the plastid to the nucleus of Arabidopsis thaliana. Proc. Natl. Acad. Sci. U.S.A. 104, 10270-10275.

Leonardos, E. D., Savitch, L. V., Hüner, N. P. A., Öquist, G., and Grodzinski, B. (2003). Daily photosynthetic and C-export patterns in winter wheat leaves during cold stress and acclimation. Physiol. Plant. 117, 521-531.

Lepisto, A. and Rintamaki, E. (2012). Co-ordination of plastid and light signalling pathways upon development of Arabidopsis leaves under various photoperiods. Mol. Plant. 5, 799-816.

Levitt, J. (1980). Responses of Plants to Environmental Stresses. Chilling, Freezing, and High Temperature Stresses, Vol. I. New York: Academic Press.

Liu, Q., Kasuga, M., Sakuma, Y., Abe, H., Miura, S., Yamaguchi-Shinozaki, K., and Shinozaki, K. (1998). Two transcription factors, DREB1 and DREB2, with an EREBP/AP2 DNA 
binding domain separate two cellular signal transduction pathways in drought- and low-temperatureresponsive gene expression, respectively, in Arabidopsis. Plant Cell 10, 1391-1406.

Masuda, T., Polle, J. E. W., and Melis, A. (2002). Biosynthesis and distribution of chlorophyll among the photosystems during recovery of the green alga Dunaliella salina from irradiance stress. Plant Physiol. 128, 603-614.

Masuda, T., Tanaka, A., and Melis, A. (2003). Chlorophyll antenna size adjustments by irradiance in Dunaliella salina involve coordinate regulation of chlorophyll a oxygenase (CAO) and Lhcb gene expression. Plant Mol. Biol. 51, 757-771.

Maxwell, D. P., Falk, S., and Hüner, N. P. A. (1995a). Photosystem II excitation pressure and development of resistance to photoinhibition I. LHCII abundance and zeaxanthin content in Chlorella vulgaris. Plant Physiol. 107, 687-694.

Maxwell, D. P., Laudenbach, D. E., and Hüner, N. P. A. (1995b). Redox regulation of light-harvesting complex II and cab mRNA abundance in Dunaliella salina. Plant Physiol. 109, 787-795.

McDonald, A. E., Ivanov, A. G., Bode, R., Maxwell, D. P., Rodermel, S. R., and Hüner N. P. A. (2011). Flexibility in photosynthetic electron transport: the physiological role of plastoquinol terminal oxidase (PTOX). Biochim.Biophys. Acta 1807, 954-967.

Melis, A. (1998). "Photostasis in plants", in Photostasis and Related Phenomena, eds R. Williams and A. Thistle (New York: Plenum Press), 207-220.

Miskiewicz, E., Ivanov, A. G., and Hüner, N. P. A. (2002). Stoichiometry of the photosynthetic apparatus and phycobilisome structure of the cyanobacterium Plectonema boryanum UTEX 485 are regulated by both light and temperature. Plant Physiol. 130, 1414-1425.

Miskiewicz, E., Ivanov, A. G., Williams, J. P., Khan, M. U., Falk, S., and Hüner, N. P. A. (2000). Photosynthetic acclimation of the filamentous cyanobacterium, Plectonema boryanum UTEX 485 , to temperature and light. Plant Cell Physiol. 41, 767-775.

Mittler, R., Vanderauwera, S., Gollery, M., and Van Breusegem, F. (2004). Reactive oxygen gene network of plants. Trends Plant Sci. 9, 490-498.

Morgan-Kiss, R. M., Priscu, J. C., Pocock, T., Gudynaite-Savitch, L., and Hüner, N. P. A. (2006). Adaptation and acclimation of photosynthetic microorganisms to permanently cold environments. Microbiol. Mol. Biol. Rev. 70, 222-252.

Mullineaux, P. M., Ball, L., Escobar, C., Karpinska, B., Creissen, G., and Karpinski, S. (2000). Are diverse signalling pathways integrated in the regulation of Arabidopsis antioxidant defence gene expression in response to excess excitation energy? Philos. Trans. R. Soc. Lond. B Biol. Sci. 355, 1531-1540.

Mullineaux, P. M., Karpinski, S., and Baker, N. R. (2006). Spatial dependence for hydrogen peroxidedirected signaling in light-stressed plants. Plant Physiol. 141, 346-350.

Murchie, E. H., Pinto, M., and Horton, P. (2009). Agriculture and the new challenges for photosynthesis research. New Phytol. 181, 532-552.

Niyogi, K. K. (1999). Photoprotection revisited: genetic and molecular approaches. Ann. Rev. Plant Physiol. Plant Mol. Biol. 50, 333-359.

Nott, A., Jung, H.-S., Koussevitzky, S., and Chory, J. (2006). Plastidto-nucleus retrograde signaling. Ann. Rev. Plant Biol. 57, 739-759.

Öquist, G., and Huüner, N. P. A (2003). Photosynthesis of overwintering evergreen plants. Ann. Rev. Plant Biol. 54, 329-355.

Padmasree, K., and Raghavendra, A. S. (2001). Consequence of restricted mitochondrial oxidative metabolism on photosynthetic carbon assimilation in mesophyll protoplasts: decrease in light activation of four chloroplastic enzymes. Physiol. Plant. 112, 582-588.

Peltier, G., and Cournac, L. (2002). Chlororespiration. Ann. Rev. Plant Biol. 53, 523-550.

Pesaresi, P., Hertle, A., Pribil, M., Kleine, T., Wagner, R., Strissel, H. et al. (2009). Arabidopsis STN7 kinase provides a link between short- and long-term photosynthetic acclimation. Plant Cell 21, 2402-2423.

Pfannschmidt, T. (2003). Chloroplast redox signals: how photosynthesis controls its own genes. Trends Plant Sci. 8, 33-41.

Pfannschmidt, T., Nilsson, A., and Allen, J. F. (1999). Photosynthetic control of chloroplast gene expression. Nature 397, 625-628.

Pfannschmidt, T. and Yang, C. (2012). The hidden function of photosynthesis: a sensing system for environmental conditions that regulates photoacclimation responses. Protoplasma 249, 125-136.

Piippo, M., Allahverdiyeva, Y., Paakkarinen, V., Suoranta, U.M., Battchikova, N., and Aro,
E.-M. (2006). Chloroplast-mediated regulation of nuclear genes in Arabidopsis thaliana in the absence of light stress. Physiol. Genomics 25, 142-152.

Quail, P. H., Boylan, M. T., Parks, B. M., Short, T. W., Xu, Y., and Wagner, D. (1995). Phytochromes: photosensory perception and signal transduction. Science 268, 675-680.

Raghavendra, A. S., Padmasree, K. and Saradadevi, K. (1994). Interdependence of photosynthesis and respiration in plant cells: interactions between chloroplasts and mitochondria. Plant Sci. 97, 1-14.

Rochaix, J. D. (2011). Regulation of photosynthetic electron transport. Biochim. Biophys. Acta 1807, 375-383.

Rodermel, S. (2001). Pathways of plastid-to-nucleus signaling. Trends Plant Sci. 6, 471-478.

Rodermel, S. (2002). "Arabidopsis variegation mutants." in The Arabodopsis Book, eds. C. R. Sommerville and E. M. Meyerowitz (American Society of Plant Biologists). Available at: http://www.bioone.org/pdfserv/ i1543-8120-030-01-0001.pdf.

Rosso, D., Bode, R., Li, W., Krol, M., Saccon, D., Wang, S., et al. (2009). Photosynthetic redox imbalance governs leaf sectoring in the Arabidopsis thaliana variegation mutants immutans, spotty, var1, and var2. Plant Cell 21, 3473-3492.

Rosso, D., Ivanov, A. G., Fu, A., GeislerLee, J., Hendrickson, L., Geisler, M. et al. (2006). IMMUTANS does not act as a stress-induced safety valve in the protection of the photosynthetic apparatus of Arabidopsis during steady-state photosynthesis. Plant Physiol. 142, 574-585.

Sakamoto, W., Miyagishima, S.-Y. and Jarvis, P. (2008). "Chloroplast biogenesis: control of plastid development, protein import, division and inheritance," in The Arabidopsis Book, eds. C. R. Sommerville and E. M. Meyerowitz (American Society of Plant Biologists). Available at: http://www.bioone.org/pdfserv/ i1543-8120-030-01-0001.pdf.

Savitch, L. V., Allard, G., Seki, M., Robert, L. S., Tinker, N. A., Hüner, N. P. A., etal. (2005). The effect of over-expression of two Brassica CBF/DREB1-Like transcription factors on photosynthetic capacity and freezing tolerance in Brassica napus. Plant Cell Physiol. 46, 1525-1539.

Savitch, L. V., Harney, T., and Hüner, N. P. A. (2000a). Sucrose metabolism in spring and winter wheat in response to high irradiance, cold stress and cold acclimation. Physiol. Plant. 108, 270-278.

Savitch, L. V., Massacci, A., Gray, G. R., and Hüner, N. P. A. (2000b). Acclimation to low temperature or high light mitigates sensitivity to photoinhibition: roles of the Calvin cycle and the Mehler reaction. Aust. J. Plant Physiol. 27, 253-264.

Savitch, L. V., Maxwell, D. P., and Hüner, N. P. A. (1996). Photosystem II excitation pressure and photosynthetic carbon metabolism in Chlorella vulgaris. Plant Physiol. 111, 127-136.

Schreiber, U., Bilger, W., and Neubauer, C. (1994). "Chlorophyll fluorescence as a nonintrusive indicator for rapid assessment of in vivo photosynthesis," in Ecophysiology of Photosynthesis, eds E. D. Schulze and M. M. Caldwell (Berlin: Springer-Verlag), 49-70.

Shikanai, T. (2007). Cyclic electron transport around photosystem I: genetic approaches. Ann. Rev. Plant Biol. 58, 199-217.

Stepien, P., and Johnson, G. N. (2009). Contrasting responses of photosynthesis to salt stress in the glycophyte Arabidopsis and the halophyte Thellungiella: role of the plastid terminal oxidase as an alternative electron sink. Plant Physiol. 149, 1154-1165.

Stitt, M., and Hurry, V. (2002). A plant for all seasons: alterations in photosynthetic carbon metabolism during cold acclimation in Arabidopsis. Curr. Opin. Plant Biol. 5, 199-206.

Strand, A., Asami, T., Alonso, J., Ecker, J. R., and Chory, J. (2003a). Chloroplast to nucleus communication trigered by accumulation of Mg-protoporphyrin IX. Nature 421, 79-83.

Strand, A., Foyer, C. H., Gustafsson, P., Gardestrom, P., and Hurry, V. (2003b). Altering flux through the sucrose biosynthesis pathway in transgenic Arabidopsis thaliana modifies photosynthetic acclimation at low temperatures and the development of freezing tolerance. Plant Cell Environ. 26, 523-535.

Strand, A., Hurry, V., Henkes, S., Hüner, N. P. A., Gustafsson, P., Gardestrom, P., et al. (1999). Acclimation of Arabidopsis leaves developing at low temperatures. Increasing cytoplasmic volume accompanies increased activities of enzymes in the Calvin cycle and in the sucrose-biosynthesis pathway. Plant Physiol. 119, 1387-1397.

Streb, P., Josse, E.-M., Gallouet, E., Baptist, F., Kuntz, M., and Cornic, G. (2005). Evidence for alternative electron sinks to photosynthetic carbon assimilation in the high mountain plant species Ranunculus glacialis. Plant Cell Environ. 28, 1123-1135. 
Sukenik, A., Wyman, K. D., Bennett, J., and Falkowski, P. G. (1987). A novel mechanism for regulating the excitation of photosystem II in a green alga. Nature 327, 704-707.

Sung, S., and Amasino, R. M. (2005). Remembering winter: toward a molecular understanding of vernalization. Ann. Rev. Plant Biol. 56, 491-508.

Tanaka, R., Koshino, Y., Sawa, S., Ishiguro, S., Okada, K., and Tanaka, A. (2001). Overexpression of chlorophyllide a oxygenase (CAO) enlarges the antenna size of photosystem II in Arabidopsis thaliana. Plant J. 26, 365-373.

Tanaka, R., and Tanaka, A. (2007). Tetrapyrrole biosynthesis in higher plants. Ann. Rev. Plant Biol. 58, 321-346.

Theocharis, A., Clemente, C., and Barka, E. A. (2012). Physiological and molecular changes in plants grown at low temperatures. Planta 235, 10911105.

Thornber, J. P., Cogdell, R. J., Chitnis, P., Morishige, D. T., Peter, G. F., Gomez, S. M., et al. (1994). "Antenna pigment-protein complexes of higher plants and purple bacteria," in Advances in Molecular and Cell Biology, Vol. 10, ed. J. Barber (London: JAI Press), 55-118.

Trevaskis, B. (2010). The central role of the VERNALIZATION1 gene in the vernalization response of cereals. Funct. Plant Biol. 37, 479-487.

Trevaskis, B., Hemming, M. N., Dennis, E. S., and Peacock, W. J. (2007).
The molecular basis of vernalizationinduced flowering in cereals. Trends Plant Sci. 12, 352-357.

Tsukagoshi, H., Busch, W., and Benfey, P. N. (2010). Transcriptional regulation of ROS controls transition from proliferation to differentiation in the root. Cell 143, 606-616.

Vanlerberghe, G. C., and McIntosh, L. (1997). Alternative oxidase: from gene to function. Ann. Rev. Plant Physiol. Plant Mol. Biol. 48 703-734.

von Gromoff, E. D., Alawady, A., Meinecke, L., Grimm, B., and Beck, C. F. (2008). Heme, a plastid-derived regulator of nuclear gene expression in Chlamydomonas. Plant Cell 20, 552-567.

Wagner, D., Przybyla, D., op den Camp, R., Kim, C., Landgraf, F., Lee, K. P. et al. (2004). The genetic basis of singlet oxygen-induced stress responses of Arabidopsis thaliana. Science 306 1183-1185.

Walters, R. G., and Horton, P. (1993). Theoretical assessment of alternative mechanisms for non-photochemical quenching of PSII fluorescence in barley leaves. Photosyn. Res. 36 119-139.

Walters, R. G., Rogers, J. J. M. Shephard, F., and Horton, P. (1999). Acclimation of Arabidopsis thaliana to the light environment: the role of photoreceptors. Planta 209, 517-527.

Wetzel, C. M., Jiang, C. Z., Meehan, L. J., Voytas, E. F. and Rodermel, S. (1994). Nuclear-organelle interactions: the immutans variegation mutant of Arabidopsis is plastid autonomous and impaired in carotenoid biosynthesis. Plant J. 6, 161-175.

Whipple, C. (2012). Defining the plant germ line: nature or nuture? Science 337, 301-302.

Whitelam, G. C., and Devlin, P. F. (1998). Light Signalling in Arabidopsis. Plant Physiol. Biochem. 36, 125-133.

Wilson, K. E., and Hüner, N. P. A. (2000). The role of growth rate, redox-state of the plastoquinone pool and the trans-thylakoid $\Delta \mathrm{pH}$ in photoacclimation of Chlorella vulgaris to growth irradiance and temperature. Planta 212, 93-102.

Wilson, K. E., Ivanov, A. G., Öquist, G., Grodzinski, B., Sarhan, F., and Hüner, N. P. A. (2006). Energy balance, organellar redox status and acclimation to environmental stress. Can. J. Bot. 84, 1355-1370.

Wilson, K. E., Krol, M., and Hüner, N.P.A. (2003). Temperature-induced greening of Chlorella vulgaris. The role of the cellular energy balance and zeaxanthin-dependent nonphotochemical quenching. Planta 217, $616-627$.

Woodson, J. D., and Chory, J. (2008). Coordination of gene expression between organellar and nuclear genomes. Nat. Rev. Genet. 9, 383-395.

Wu, D., Wright, D. A., Wetzel, C. Voytas, D. F., and Rodermel, S. (1999). The IMMUTANS variegation locus of Arabidopsis defines a mitochondrial alternative oxidase homolog that functions during early chloroplast biogenesis. Plant Cell 11, 43-56.

Yu, F., Fu, A., Aluru, M., Park, S., Xu, Y., Liu, H., et al. (2007). Variegation mutants and mechanisms of chloroplast biogenesis. Plant Cell Environ. 30, 350-365.

Conflict of Interest Statement: The authors declare that the research was conducted in the absence of any commercial or financial relationships that could be construed as a potential conflict of interest.

Received: 16 August 2012; accepted: 30 October 2012; published online: 20 November 2012.

Citation: Hüner NPA, Bode R, Dahal K, Hollis L, Rosso D, Krol $M$ and Ivanov AG (2012) Chloroplast redox imbalance governs phenotypic plasticity: the "grand design of photosynthesis" revisited. Front. Plant Sci. 3:255. doi: 10.3389/fpls.2012. 00255

This article was submitted to Frontiers in Plant Physiology, a specialty of Frontiers in Plant Science.

Copyright (C) 2012 Hüner, Bode, Dahal, Hollis, Rosso, Krol and Ivanov. This is an open-access article distributed under the terms of the Creative Commons Attribution License, which permits use, distribution and reproduction in other forums, provided the original authors and source are credited and subject to any copyright notices concerning any thirdparty graphics etc. 